\title{
PREVALENCE OF OSTEOARTHRITIS AND RHEUMATOID ARTHRITIS CASES REQUIRING TOTAL HIP OR KNEE ARTHROPLASTY AND ESTIMATED POPULATION PREVALENCE
}

Catrine Rangel Maia ${ }^{1}$, Martha Cecilia Castaño-Betancourt ${ }^{1, \star}$, Karoline Ribeiro Rosa ${ }^{1}$, Monica Vannucci Nunes Lipay ${ }^{1}$, Evaldo Marchi ${ }^{1}$

1.Faculdade de Medicina de Jundiaí, Jundiaí (SP), Brazil.

*Corresponding author: castanomc@yahoo.es

\section{BACKGROUND}

Osteoarthritis (OA) and rheumatoid arthritis (RA) are the most common joint diseases in the elderly population. In Brazil, the prevalence of RA in adults varies between 0.2 and $1 \%$, affecting more women, between 30 and 50 years old. Symptomatic OA mainly affects people over 60 and is considered a major cause of joint pain and disability principally in females. In Brazil, there are no accurate estimates of the prevalence of $\mathrm{OA}$ in the elderly, and the percentage of people with RA and advanced OA who require arthroplasty is unknown. Our objectives were to determine the prevalence of RA and OA cases requiring total joint arthroplasty (TJA) and, from these values, to estimate the prevalence of OA and RA in our population.

\section{MATERIALS AND METHODS}

In 2019, we examined medical records of patients who attended the orthopedics outpatient clinic, referred from other services, and diagnosed with OA or RA. All patients had radiographic evidence of advanced hip and/or knee joint wear and persistent pain without response to conservative treatment. Orthopedic consultation to the hospital allows the assessment of the possibility of TJA. The diagnosis and severity of the disease were verified by specialists. We estimated the general prevalence considering that in 2019, the municipality had an estimated total population of 418,962 inhabitants, $18 \%$ between $35-60$ and $12 \%$ older than 60 years. Of them, 38\% exclusively use public health services.

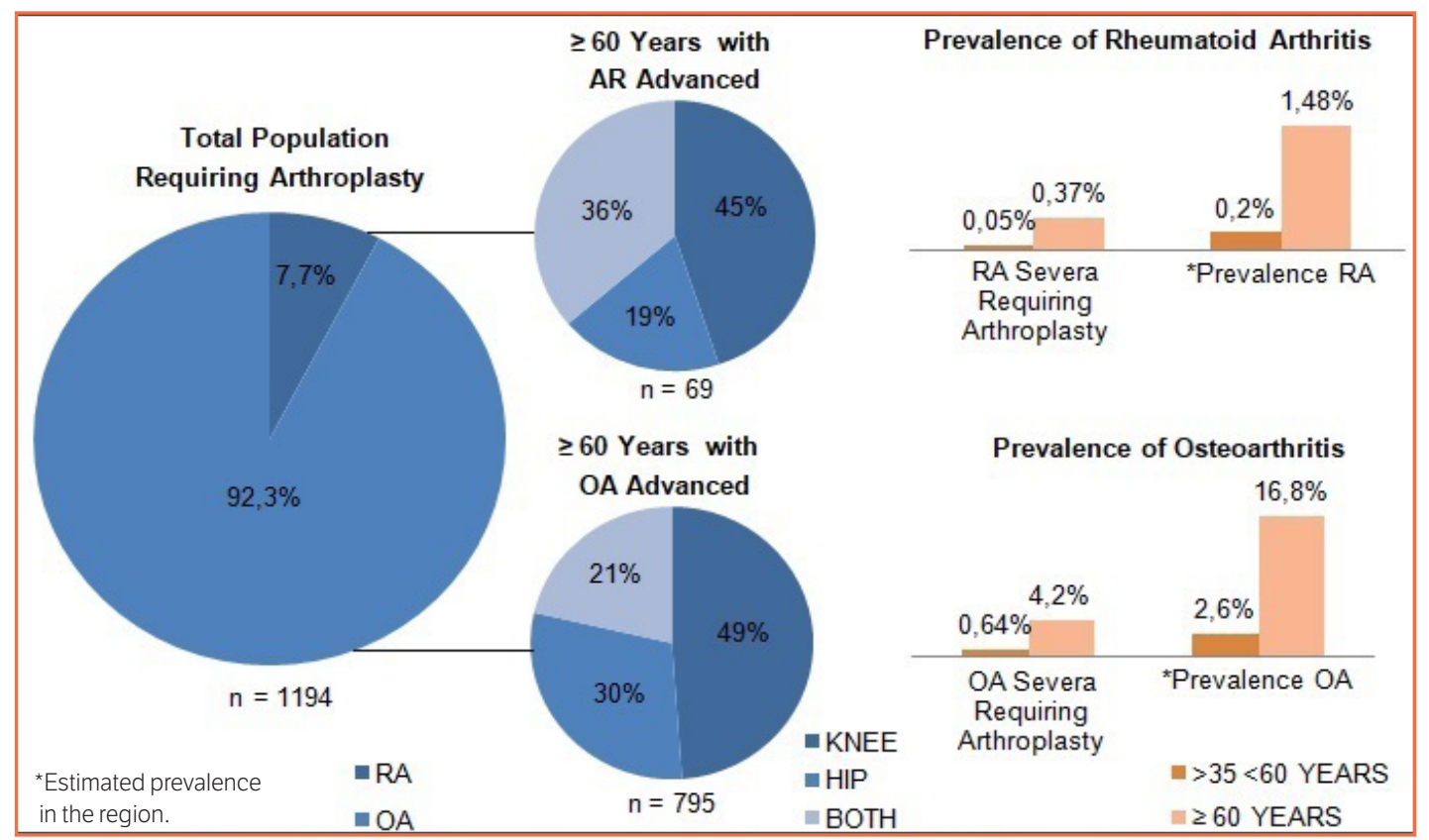

Figure 1. Prevalence of hip or knee osteoarthritis (OA) a rheumatoid arthritis (RA) in our population. 


\section{RESULTS}

There were 1194 patients in the hospital's electronic medical records. From them, 1102 (92.3\%) were diagnosed with osteoarthritis, $72.1 \%$ were aged 60 years or older $(n=795)$ and $62.3 \%$ were women. Patients with OA had knee affected $(49 \%)$, hip $(30 \%)$, with both joints affected (21\%). The other 92 patients (7.7\%) received a diagnosis of RA, $75 \%$ aged 60 years or older $(n=69)$ and $88.4 \%$ of them women. Patients with RA and over 60 years old, had knee affected (45\%), hip (19\%), and 36\% had both affected joints. Considering the total population and percentage of public service users, the estimated prevalence of advanced OA and RA requiring total hip or knee arthroplasty is $4.2 \%$ and $0.37 \%$, respectively (Fig. 1 ).

\section{CONCLUSIONS}

Considering that approximately 1 in 4 adults with advanced $O A$ and RA require arthroplasty for severe pain and difficulty walking, the estimated prevalence of hip and knee OA and RA in the population aged 60 or over would be approximately $16.8 \%$ and $1.5 \%$, respectively, with the knee being the most affected joint.

\section{ACKNOWLEDGEMENTS}

Fundação de Amparo à Pesquisa do Estado de São Paulo (FAPESP Grant number 2016/21039-0 and 2019/21326-8). 